Ljubljana

\title{
DE NONNULLIS VOCIBUS IN LEXICO LATINITATIS MEDII AEVI IUGOSLAVIAE (A - P) OBVIIS
}

aretium? - rete ligneum: cf. textum: ".. armarium pulcrum fornitum aretiis".

2. armarum? - idem valet atque 1. armarum "canalis, cloaca"

blanconcellus? - idem est ac balconcellus "parvum maenianum".

cardinus? - idem atque cardinum, ital. giardino.

climen? - lege: flumen, cf. textum:" ... et affluet flumen (corr. ex: climen) aquis, vadat pars".

cusverium? - lege: custellerium (acc. m.), cf. s. v. custellerius "pugio, sica". Textus est: "Et exportavit furtone (i. e. furtive) unum cusverium argenti".

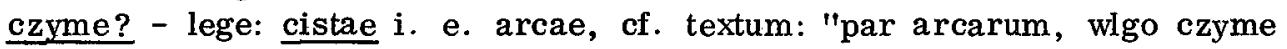
..."

desdare? - mittere.

fontaliis? - lege: frontaliis (= -ibus), parte frontali, ef. textum: ".. palla de auro in campo albo sine frontalibus (corr. ex: fontaliis) et sine angulis ...".

interpletaxare? - textus sic sanandus est: "... panes candidissimos ipsis in triplex taxant (corr. ex: interpletaxant), aquam ex puteis absque penuriali pretio haurire non sinunt".

2. laudum? - e loco, quem Rački Documenta 124/35, a. 1066 affert: "... cereum laudum ...", laudum candelam significare apparet. Cf. p. 207 s. v. cereus, m: cereus laudum - cereus qui accenditur, cum in officio divino Laudes canuntur ..."

privo, priuo? - locus: "... teneantur laborare ... tres hebdomadas sine priuo" sic est interpretandus: nullo die ad privatos labores obeundos seposito.

proniventibus? - hic de captivis redimendis agitur: "... teneatur ... rex de captivis predictis dare ... excambiat pro viventibus ..."

Povzetek

O NEKATERIH BESEDAH V LEXICON LATINITATIS MEDII AEVI IUGOSLAVIAE (A - P)

Avtor je poskusil pojasniti nekatere besede, ki so ostale nejasne. 